\title{
Asociación entre medio ambiente y salud pública: El caso del incendio del Relleno Sanitario en Mineral de la Reforma, Hidalgo, México
}

\author{
Association between environment and public health: The case of the Sanitary Landfill fire in \\ Mineral de la Reforma, Hidalgo, Mexico
}

Jarentzy Cruz Olvera ${ }^{a}$

\begin{abstract}
:
This article denotes the information circulating in the newspaper the independent regarding the fire that occurred on May 11 of the present in the landfill of Mineral de la Reforma in Hidalgo and confirms that the environment is definitely a condition of health , the situation is focused on its association with the health disease process and that was not accepted by authorities in this regard, but in situations such as the one experienced by the environmental contingency, they confirm this association.
\end{abstract}

Keywords:

association with acute and chronic diseases, environmental contingency, fire, landfill

\section{Resumen:}

El presente artículo denota la información circulante en el periódico el independiente respecto al incendio ocurrido el día 11 del mes de mayo del presente en el relleno sanitario de Mineral de la Reforma en Hidalgo y se confirma que definitivamente el medio ambiente es un condicionante de la salud, situación en la se centra su asociación con el proceso salud enfermedad y que no se aceptaba por autoridades al respecto, pero que ante situaciones como la vivida por la contingencia ambiental confirman dicha asociación.

\section{Palabras Clave:}

asociación con enfermedades agudas y crónicas, contingencia ambiental, incendio, relleno sanitario

\section{Introducción}

El sábado 11 del mes de mayo del 2018 ocurrió un incendio en el relleno sanitario del mineral de la reforma y de inmediato se alteraron las condiciones ambientales ene I municipio y de manera significativa en la ciudad de Pachuca Hidalgo, se anunció que por la tarde este había suido controlado, sin embargo las condiciones ambientales habían sido modificadas con bastante intensidad en cuanto a la presencia de inversión térmica y la gran cantidad de humos emitidos aun por este hallazgo el lunes 14 del presente, las acciones derivadas de la contingencia ambiental manifestaron su decisión de suspender clases y emitir recomendaciones al respecto.
El relleno sanitario no cumple con la normatividad para operar como tal, aunque ya tenía llamada de atención definidamente se clausuro dicho nicho contaminante.

Luego de este incendio la alcaldía anuncio que existe una denuncia por daño ambiental que presento la secretaria de medio ambiente y recursos naturales misma que se aplicara a quien resulte responsable.

La secretaria de medio ambiente y recursos naturales de hidalgo, emitió una alerta amarilla por calidad de aire regular. Derivado de los acontecimientos señalados el gobierno debió emitir una alerta para evitar la exposición de contaminantes tales como hidrocarburos, co2, entre otros, aunque la CEMARNAT de hidalgo señalo que la calidad de aire era buena, lo cual no permite tener confianza en estas mediciones si definitivamente existe la posibilidad de exposición.

Lo anterior nos lleva a plantear la siguiente pregunta de investigación:

\footnotetext{
${ }^{a}$ Estudiante de la Maestría en Salud Pública en Instituto Elise Freinet, Pachuca de Soto, Hidalgo. Autor de correspondencia. Email: jarentzy@hotmail.com
} 
¿Cuál es el impacto en vías respiratorias de los humos y PM10en personas expuestas durante el incendio del relleno sanitario el predio la cañadas del mineral de la reforma, Hidalgo, México?

Una limitante respecto al análisis de esta información corresponde a que prácticamente solo se utilizó la información publicada de una sola fuente "periódico el independiente" y que no se hace comparación contra otras fuentes de información, sin embargo el lector notara que existe una lógica en el seguimiento que hacen los editores de este periódico y que en si se manifiesta lo que en verdad ocurrió.

Conclusión: el medio ambiente es un condicionante de la salud, el cuidado de este corresponde a toda la sociedad, ya que en el se manifiestas la vida y la salud y que el impacto negativo como resultado, produzca enfermedades agudas o bien crónicas y que se manifiesta en la población, aquel que piense que solo impacta a un parte de la población humana, muy probablemente no se considera o no considera el resto de la población como parte de este entorno y que se requiere en condiciones óptimas para evitar riesgos y estados de salud que ponen en peligro la estabilidad y continuidad de la vida humana.

\section{Opinión}

Me parece que hablar de contaminación ambiental en muchas de las ocasiones pude llegar a ser controversial y no solo por la repercusiones tan drásticas que esto con lleva sino que pueden generar diferentes puntos de vista sobre todo para aquellas personas en las cuales por su carácter de responsabilidad social y civil puede lastimar en los más profundo de su ineficiencia y pronta respuesta para tratar de resarcir un daño que en ocasiones es indiscutiblemente irreversible.

A lo largo de la historia se han registrado grandes catástrofes en los que la mano del hombre ha tenido que ver con todas sus serias e irreversibles repercusiones que esto conlleva, consecuencias que aun en nuestros tiempos se ve reflejado como resultado del daño registrado.

Es un hecho claro que la corrupción es un pilar que sirve como trasfondo dentro de las principales causas por las cuales resulto un desastre y que por lo tanto genero un grado de contaminación en el medio ambiente y esto se genera desde los muy bajos hasta los mas altos niveles, desde microempresas hasta las macroempresas.

Como en un momento dado ya se había descrito por parte de Blum y LaLonde hace algunos años, el factor ambiental es y ha sido unos de los determinantes más importantes de salud en el ser humano, ya que si se ve afectado a través de una contaminación por aire, suelo, y/o agua tarde que temprano se reflejará en el nivel de salud tanto en los colectivo como en lo individual y es una situación que desde que se dio a conocer no ha dejado de persistir como tal.

Es imprescindible que la educación que se recibe en casa sea uno de los mayores pilares para fomentar como cultura en las próximas generaciones la adecuada clasificación y disposición de los residuos que generamos día con día y sobretodo evitar el uso indiscriminado de fuentes de contaminación como el uso de fogatas, quema de llantas, arrojar basura en la calle y que estas obstaculicen el drenaje, tener el hábito de reciclar por mencionar algunos y sobretodo cuidar los recursos con los que actualmente se cuenta para heredarlos a próximas generaciones.

\section{Conclusión}

Concluyo haciendo referencia que lo ocurrido en el relleno sanitario del mineral de la Reforma se convirtió en una verdadera emergencia en salud publica ya que afecto a gran parte de la población de ese lugar y municipios circunvecinos y que si se midiera el grado de afectación podríamos quedarnos cortos con lo antes mencionado.

\section{Referencias}

[1] Ruvalcaba Ledezma J. C., Asociación entre medio ambiente y salud pública: El caso del incendio del Relleno Sanitario en Mineral de la Reforma, Hidalgo, México. Educación y Salud Boletín Científico de Ciencias de la Salud del ICSa 2018; 7(13): 96-98. 